\title{
A dynamic panel analysis using SIPRI's extended military expenditure data: The case of Middle Power nations
}

\section{Mohamed Douch and Binyam Solomon}

Mohamed Douch, the corresponding author, is Associate Professor, Management and Economics Department, Royal Military College of Canada, Kingston, Ontario, Canada. He may be reached at mdouch@mdouch.net. Binyam Solomon is Senior Defence Scientist, Defence Research and Development, Department of National Defence, and Adjunct Professor, Carleton University, both in Ottawa, Canada. He may be reached at binyam.solomon@forces.gc.ca.

\section{Abstract}

This study employs SIPRI's extended military expenditure dataset to estimate a dynamic panel analysis of Middle Powers' defense posture. The dynamic approach, particularly the Auto Regressive Distributed Lag (ARDL) approach, permits simultaneous, but separate, assessment of short- and long-run effects of a particular variable on military expenditure. We verify the robustness of earlier findings on Middle Power nations' defense posture. In particular, their military expenditure tends to an income elasticity of greater than one indicating that military power is, at least in part, a status good. In addition, Middle Powers react to threat variables that proxy global instability, such as nuclear power proliferation, and they use foreign aid as a complementary policy tool. Competing demands for funds lead to significant tradeoffs between military and nonmilitary government spending.

$\mathrm{T}$ he Stockholm International Peace Research Institute (SIPRI) is expected to release the final, public version of its extended military expenditure dataset in late 2016. This dataset is expected to cover over 170 countries for the period 1961 to 2014 and, in a number of cases, extends back to 1950. (The current version covers 1988 to 2015). This article uses the alpha version of the new dataset to reestimate the demand for military expenditure of Middle Power nations and to validate the dataset by comparison with official national and NATO statistics. ${ }^{1}$

To preview the findings, the use of the new SIPRI dataset essentially replicates previous results even as it enabled us to include two additional Middle Power nations in the study (Ireland and Spain, identified as a Middle Powers in an earlier study but omitted there due to data limitations). ${ }^{2}$ The new dataset also permits us to apply a dynamic panel estimation technique, further validating the robustness of our earlier findings.

The key findings in this article include the following:

1. Middle Power nations' military expenditure tends to exhibit an income elasticity of greater than one, indicating that military power is, at least in part, a status good.

2. Middle Power nations react to threat variables that proxy global instability, such as nuclear power proliferation.

3. Middle Power nations use foreign aid as a complementary policy tool, along with military expenditure.

4. Middle Power nations face significant tradeoffs between military and nonmilitary government spending.

The data validation exercise we conducted using NATO's official statistics and Canadian national data show some notable deviations particularly in the later years of the dataset. These deviations are due to NATO's changes in definition and to NATO's failure to link its time series for consistency (that is, data is not updated backward to keep consistent definitions throughout the time series). We therefore suggest that for empirical analyses and cross-country comparisons, the SIPRI dataset be used, as consistency is maintained over the whole of its time series.

The remainder of this article is structured as follows. The next section briefly discusses what we mean by the Middle Powers. The sections thereafter presents the data and the reestimation of Middle Powers' demand for military expenditure with emphasis placed on the key differences in estimation approaches, dynamics, and key findings. The final section concludes and suggests new research directions.

\section{Middle Powers and their military expenditure}

From an economics perspective, the determinants of military expenditure can be derived from standard social welfare optimization models and alliance theory. Generally speaking, these models show that the key drivers of demand for military expenditure are income constraints, threats, military alliances (degree of publicness of military expenditure), and specific demand shift variables. But questions remain. For example, 
how is threat perceived when a nation does not have a known adversary? Or, do nations use military expenditure as a status good? Are there competing or complementary policy tools that can be used instead of or alongside military expenditure? ${ }^{3}$

In an earlier study, published in 2014, we address such issues for nine nations identified as Middle Powers. That study did show policy complementarity between military expenditure and foreign aid and identified nuclear proliferation indicators as proxies for global instability and as likely threat variables for Middle Power nations. While the study identified a high income elasticity of military expenditure (i.e., higher national income is statistically associated with higher military expenditure), an elasticity of greater than one could only be established for selected Middle Power nations. ${ }^{4}$

One of the drawbacks of the 2014 study pertained to data limitations. Even though the time series used in the study covered over 50 years of data, it extended to only nine Middle Powers. From a technical, econometric perspective, the use of fixed effects panel estimation is inappropriate when the number of cases (9) is smaller than the time series (50+). Moreover, while two additional nations were identified as Middle Powers (Ireland and Spain), the lack of consistent time series excluded their inclusion in the 2014 study. In this article, in contrast, Ireland and Spain are included on account of the extended SIPRI dataset. In addition, we use the Auto Regressive Distributed Lag (ARDL) approach to better assess the dynamics of the model. ${ }^{5}$

\section{Data}

As noted, data on the military expenditure for the period 1961 to 2014 (in constant 2011 U.S. dollars) are available in the new SIPRI dataset. The 11 nations included in the analysis here are Australia, Belgium, Canada, Denmark, Finland, Ireland, Italy, the Netherlands, Norway, Spain, and Sweden. Spain is deemed to be a Middle Power after 1980, i.e., for the post-Franco period. Military expenditure for the United States is included in the study as well, as a proxy for the dominant NATO ally.

GDP figures for the 11 nations and deflators to convert foreign aid data from the OECD are obtained from the World Bank's online data facility. To reflect tradeoffs faced by nations between socioeconomic and security needs, government expenditure was obtained from the World Bank as well (removing military expenditure and foreign aid from the aggregate). The main threat variables - the size of the strategic arsenal — was provided by Jim Finan (Royal Military College, Canada). Specifically, these refer to the number of nucleartipped intercontinental missiles, the nuclear total arsenal, and the potential yield of nuclear explosions. In addition, we use conflict casualties data from the Peace Research Institute,
Olso's (PRIO) armed conflict dataset. In the present study we also include Doomsday Clock data from the Bulletin of the Atomic Scientists to amplify our 2014 argument that, in the absence of country-specific or regional adversaries, Middle Powers react to global instability proxies. ${ }^{6}$

\section{Method}

As indicated, this study uses a panel data set which includes data for 11 Middle Power countries. By employing advanced dynamic panel techniques, such as Autoregressive Distributive Lag (ARDL) estimation, one can capture the dynamic nature of the data and present empirical evidence about the relationship between and among military expenditure, threat perception, and so on as outlined beforehand. Static models, such as fixed and random effects models, were not considered due to their inability to capture the data dynamics which is crucial in determining any short- and long-term relationships that may be present in the data. Further, the ARDL approach allows one to simultaneously, but separately, assess both the short- and long-run effect of a particular variable on military expenditure. $^{7}$

The GMM system estimators developed by Arellano and Bond and Arellano and Bover are competing techniques suitable for panel data analysis but known to suffer from certain shortcomings. For example, GMM is unable to capture long-run data dynamics. These estimators were, therefore, not used in this study. The ARDL approach is based on Pesaran and on Pesaran, Shin, and Smith where dynamics are incorporated into an error correction model by using lags of the dependent and independent variables. This allows for rich dynamics in the sense that the dependent variable adapts to changes in the explanatory variables. ${ }^{8}$

The ARDL $\left(\mathrm{p}, \mathrm{q}_{1}, \ldots, \mathrm{q}_{\mathrm{k}}\right)$ technique, where $p$ is the lag of the dependent variable and $q_{j}$ is the lag of the independent variables $(j=1,2, \ldots, k)$ can be stated as follows:

$$
\text { (1) } \text { Milex }_{i t}=\sum_{j=}^{p} \lambda_{i j} \text { Milex }_{i, t-j}+\sum_{j=0}^{q} \beta_{i j} X_{i, t-j}+\mu_{i}+\varepsilon_{i t} \text {, }
$$

where $i=1,2, \ldots, 11$ is an index for the eleven countries; $t=1$, $2, \ldots, \mathrm{T}$ is an index for time; $X_{i t}$ is a $k \times 1$ vector of explanatory variables (income, threat variable, U.S. military expenditure, and other government spending); $\beta_{i t}$ are the $k \times 1$ coefficient vectors; $\lambda_{i t}$ are scalars; and $\mu_{i}$ is the country-specific effect. The time period $T$ must be large enough such that the model can be fitted for each country separately. Constant term, time trends, and other fixed regressors may be included. Following the discussion in Pesaran, Shin, and Smith, and if the variables in (1) are, for example, I(1) and cointegrated, then the error term is an $\mathrm{I}(0)$ process for all $i .^{9}$ This feature implies an error 
Table 1: Long-run coefficients, 1961-2014

$\begin{array}{lccccc}\text { Variable } & \text { Model 1 } & \text { Model 2 } & \text { Model 3 } & \text { Model 4 } & \text { Model 5 } \\ \text { GDP } & 2.03^{* * *} & 1.49 * * * & 1.37 * * * & 1.55^{* * *} & 1.2 * * * \\ \text { Threat (-1) } & 0.21 * * * & 0.06 * & 0.38 & -0.02 & 0.9 * * * \\ \text { MainAlly (-1) } & -0.1 & -0.23^{* *} & -0.69 * * & -0.3 & -0.14 * \\ \text { OtherGovExp } & -1.14 * * * & -1.16^{* * *} & -1.21 * * * & -0.92 * * * & -0.36 * * \\ \text { ODA } & 0.21 * * * & 0.52 * * * & 0.82 * * * & 0.22 * * * & 0.03\end{array}$

Notes: $* * * * *, *$ reflect statistical significance at the $1 \%, 5 \%$, and $10 \%$ levels. Threat variables used in Models 1 to 5 are, respectively, total nuclear arsenal, nuclear intercontinental missiles, Doomsday Clock, conflict casualties, and nuclear explosion. MainAlly is U.S. military expenditure; OtherGovExp is other government expenditures; ODA is foreign aid.

Table 2: Short-run coefficients, 1961-2014

$\begin{array}{lccccc}\text { Variable } & \text { Model 1 } & \text { Model 2 } & \text { Model 3 } & \text { Model 4 } & \text { Model } 5 \\ \text { ConEq1 } & -0.09^{* * *} & -0.07 * * & -0.03 & -0.05^{* *} & -0.11^{* * *} \\ \Delta \text { GDP } & 0.35^{* * *} & 0.4 * * * & 0.46^{* * *} & 0.39 * * * & 0.39 * * * \\ \Delta \text { Threat(-1) } & 0.14^{* * *} & 0.02 & -0.02 & 0.01 & 0.001 \\ \Delta \text { MainAlly }(-1) & 0.11^{* *} & 0.11^{* *} & 0.11^{* *} & 0.11^{* *} & 0.12 * * \\ \Delta \text { OtherGovExp } & 0.44^{* * *} & 0.44^{* * *} & 0.43^{* * *} & 0.47 * * * & 0.41 * * * \\ \Delta \text { ODA } & -0.02 * & -0.03 * & -0.02 & -0.02 & -0.02 \\ \beta 0 & -0.68 * * * & 0.08 & 0.18 & 0.07 * & -0.13 * * *\end{array}$

Notes: See Table 1. In addition, $\beta 0$ is the intercept term; ConEq1 is the co-integration equation.

correction model in which the short-run dynamics of the variables in the system are influenced by the deviation from equilibrium. Thus it is common to reparametrize equation (1) into the following error correction equation:

$$
\begin{aligned}
& \left.\Delta \text { Milex }_{i t}=\phi_{i} \text { Milex }_{i, t-1}-\theta_{i}^{\prime} X_{i, t}\right) \\
& +\sum_{j=}^{p-1} \lambda_{i j}^{*} \Delta \text { Milex }_{i, t-j}+\sum_{j=0}^{q-1} \beta_{i j}^{*} \Delta X_{i, t-j}+\mu_{i}+\varepsilon_{i t}
\end{aligned}
$$

where $\Delta$ is the first difference operator; and

$$
\begin{aligned}
& \phi_{i}=-\left(1-\sum_{j=1}^{p} \lambda_{i j}\right) ; \theta_{i}=\sum_{j=0}^{p} \beta_{i j} /\left(1-\sum_{k} \lambda_{i k}\right) \\
& \lambda_{i j}^{*}=-\sum_{m=j+1}^{p} \lambda_{i m}, \mathrm{j}=1,2, \ldots, \mathrm{p}-1 ; \beta_{i j}^{*}=-\sum_{m=j+1}^{q} \beta_{i m}, \mathrm{j}=1,2, \ldots, \mathrm{q}-1 .
\end{aligned}
$$

Of interest are the error-correcting speed of adjustment term, that is, the parameter $\phi_{i}$, and the vector $\theta_{i}$, which contains the long-run relationships between the variables. The error-correcting term is expected to be negative in a statistically significant way under the prior assumption that the variables return to a long-term equilibrium.

In the recent literature on dynamic panel regressions, three techniques are used, dynamic fixed effects, mean group (MG), and pooled mean group (PMG) estimations. The choice among the three is determined by employing the joint Hausman test. In our case, PMG is preferred to both MG and DFE. Results shown in the next section thus omit both DFE and MG. (They are available upon request.)

\section{Results}

Table 1 presents the estimated long-run coefficients for the panel of Middle Power nations using the PMG estimator. The estimated model includes Ireland and Spain and the time period covered (1961-2014) includes more of the post-cold war period than our previous study (1952-2007).

As shown in Table 1, regardless of the threat variables used (indicated in Models 1 to 5) the GDP or income elasticity of Middle Powers' military expenditure exceeds 1. This is consistent with the theoretical prediction that Middle Powers use military expenditure as a positional good. Significant tradeoffs in government expenditure due to competing demands is another characteristics of Middle Power nations. This is shown by the large and statistically significant negative effects of other government expenditure. Similarly, we find statistically significant results for the policy complementarity of foreign aid.

While our 2014 study found all threat variables to be statistically significant, in this study only three are found to be statistically significant, two the at 1 percent level and one at 10 percent level. The new threat variable included in this study, Doomsday Clock, and the conflict casualties variable are not statistically significant. In future studies, the size of the total nuclear arsenal and the nuclear explosion yields may be the preferred global instability proxies. ${ }^{10}$

U.S. military expenditure as a proxy of the dominant ally 
Table 3: Long-run effects, cold war and post-cold war years

$\begin{array}{lcc}\text { Variable } & \begin{array}{c}\text { Cold war } \\ (1961-1990)\end{array} & \begin{array}{c}\text { Post-cold war } \\ (1991-2014)\end{array} \\ \text { GDP } & 0.6^{*} & 1.51^{* * *} \\ \text { Threat }(-1) & -0.59^{* * *} & 0.01 \\ \text { MainAlly (-1) } & 0.24^{*} & -0.3^{* * *} \\ \text { OtherGovExp } & 0.33 & -0.61 \\ \text { ODA } & 0.1 * * * & -0.05\end{array}$

Note: The threat proxy used here is the size of the total nuclear arsenal.

shows a statistically significant and negative relation to Middle Powers' military expenditure. This possibly points to freeriding by Middle Powers, but the results are not robust across the various threat proxies.

In regard to the short-run dynamics, the estimated coefficients shown in Table 2 suggest a more theoretically consistent relation to U.S. military spending. Specifically, U.S. military spending affects Middle Powers' military expenditure in a statistically significant and positive way. Also notable is that other government spending inertia tends to dominate the short-run dynamics for Middle Powers.

The new SIPRI dataset also permits us to separately test the military expenditure behavior of Middle Power nations during the cold war and post-cold war periods. Thus, Table 3 shows an income elasticity of greater than one irrespective of the time period. However, the magnitude is larger during the post-cold war years. The threat variable is statistically significant only for the cold war years, the (potential) free-riding variable switches signs, and the other two variables are not statistically significant. These are rather diverse findings that may warrant further investigation.

\section{Conclusion}

The forthcoming expansion of SIPRI's military expenditure data back to the early 1960 s is welcome news to researchers. Longer time series, starting, for most countries, as from 1961 will allow for more dynamic and robust estimation of models using the military expenditure data. Our own recent (2014) work on the military expenditure behavior of Middle Power nations has benefitted from this backward extension of SIPRI's time series. Specifically, it allowed the inclusion of data for two additional nations previously identified as Middle Powers. Our main findings in the study mostly concur with those of our earlier study. Middle Powers' military expenditure tends to show income elasticity of greater than one, they react to threat variables that proxy global instability, such as military-nuclear power proliferation, they appear to use foreign aid as a complementary policy tool, and tradeoffs between military and nonmilitary government spending are observed in the data.

Although not detailed here, it should be pointed out that the new SIPRI dataset permits researchers to reassess official NATO and country-specific military expenditure-related data. SIPRI's use of a (fairly) consistent definition over the range of its time series allows researchers to conduct cross-country estimation and analyses. In contrast, NATO's official statistics do not update previous data to match changes in definitions while country data tend to be specific to national legislative or expenditures management requirements, and this limits their use in robust cross-country comparisons.

We believe that future studies should continue to use nuclear arsenal-related proxies as a threat measure, especially for nations with no known country-specific adversary. An extension to our models ought to look at the possibility of nonlinear dynamics of military expenditure pattern as nations transit from less to more inclusive economies and polities.

\section{Notes}

We are grateful to Professor James Finan for providing updated data on threat variables and for his continuous help throughout the project. The authors also thank this journal's editor as well as an anonymous referee for constructive comments and suggestions.

1. SIPRI released the alpha version to selected researchers in late 2015.

2. The earlier study is Douch and Solomon (2014).

3. Social welfare optimization models: See, e.g., Smith (1989; 1985). Alliance theory: See, e.g., Murdoch and Sandler (1982).

4. The classification and selection of Middle Powers is discussed in Douch and Solomon (2014) and it is not repeated here.

5. Technical aspect of fixed effects panel: Breitung and Pesaran (2008). Thus, Douch and Solomon (2014) employed seemingly unrelated regression equations (SURE) instead of a fixed effect panel estimation.

6. PRIO: http://www.pcr.uu.se/research/ucdp/datasets/ucdp prio_armed_conflict_dataset/. Doomsday Clock: See http://thebulletin.org/overview. [Both accessed 14 February 2016].

7. Simultaneously, but separately: Bentzen and Engsted (2001).

8. GMM: Arellano and Bond (1991); Arellano and Bover (1995). GMM shortcomings: Samargandi, Fidrmuc, and Ghosh (2015). Unable to capture long-run dynamics: Eberhardt 
(2012). ARDL approach: Pesaran (1997); Pesaran, Shin, and Smith (2001).

9. Pesaran, Shin, and Smith (2001). The ARDL approach may be applied to time series variables irrespective of whether they are $\mathrm{I}(0)$, I(1), or mutually cointegrated (Pesaran and Shin 1999). This makes testing for unit roots unnecessary.

10. Unlike the other threat variables used in the study, the Doomsday Clock variable works in reverse so that a negative relationship is expected: The fewer the minutes left to "midnight," the graver the threat.

\section{References}

Arellano, M. and S. Bond. 1991. "Some Tests of Specification for Panel Data: Monte Carlo Evidence and an Application to Employment Equations." Review of Economic Studies. Vol. 58, No. 2, pp. 277-297. http://dx.doi.org/10.2307/2297968

Arellano, M. and O. Bover. 1995. "Another Look at the Instrumental Variable Estimation of Error-Components Models." Journal of Econometrics. Vol. 68, No. 1, pp. 29-51. http://dx.doi.org/10.1016/0304-4076(94)01642-D

Bentzen, I. and T. Engsted. 2001. "A Revival of the Autoregressive Distributed Lag Model in Estimating Energy Demand Relationship.” Energy. Vol. 26, No. 1, pp. 45-55. http://dx.doi.org/10.1016/S0360-5442(00)00052-9

Breitung, J. and H. Pesaran. 2008. "Unit Roots and Cointegration in Panels," pp. 279-322 in L. Matyas and P. Sevestre, eds. The Econometrics of Panel Data: Fundamentals and Recent Developments in Theory and Practice. 3rd ed. Dortrecht: Kluwer. http://dx.doi.org/10.1007/978-3-540-75892-1_9

Eberhardt, M. 2012. "Estimating Panel Time-Series Models with Heterogeneous Slopes.” Stata Journal. Vol. 12, No. 1, pp. 61-71.

Douch, M. and B. Solomon. 2014. "Middle Powers and the Demand for Military Expenditures." Defence and Peace Economics. Vol. 25, No. 6, pp. 605-618. http://dx.doi.org/10.1080/10242694.2013.861652

Murdoch, J.C. and T. Sandler. 1982. "A Theoretical and Empirical Analysis of NATO." Journal of Conflict Resolution. Vol. 26, No. 2, pp. 237-263. http://dx.doi.org/10.1177/0022002782026002003

Pesaran, H. 1997. "The Role of Econometric Theory in Modeling the Long Run." Economic Journal. Vol. 107, No. 440, pp. 178-191. http://dx.doi.org/10.1111/1468-0297.00151

Pesaran, H. and Y. Shin. 1999. “An Autoregressive Distributed Lag Modeling Approach to Cointegration in Econometrics and Economic Theory in the 20th Century," pp. 371-413 in S. Strom, ed. The Ragnar Frisch Centennial Symposium. New York: Cambridge University Press.

Pesaran, H., Y. Shin, and R. Smith. 2001. "Bounds Testing Approaches to the Analysis of Level Relationships."
Journal of Applied Econometrics. Vol. 16, No. 3, pp. 289326.

http://dx.doi.org/10.1002/jae.616

Samargandi, N., J. Fidrmuc, and S. Ghosh. 2015. "Is the Relationship between Financial Development and Economic Growth Monotonic? Evidence from a Sample of Middle-Income Countries." World Development. Vol. 68, No. 1, pp. 66-81. http://dx.doi.org/10.1016/j.worlddev.2014.11.010

Smith, R. 1989. "Models of Military Expenditure." Journal of Applied Econometrics. Vol. 4, No. 4, pp. 345-359. http://dx.doi.org/10.1002/jae.3950040404

Smith, R. 1995. "The Demand for Military Expenditure," pp. 69-87 in K. Hartley and T. Sandler, eds. Handbook of Defense Economics. Vol. 1. Amsterdam: North Holland. 